\title{
Two Childhood Pheochromocytoma Cases due to von Hippel-Lindau Disease, One Associated with Pancreatic Neuroendocrine Tumor: A Very Rare Manifestation
}

\author{
(D) Aydilek Dağdeviren Çakır ${ }^{1}$, (D) Hande Turan ${ }^{1}$, (D) Ayça Aykut², (D) Asude Durmaz², (D) Oya Ercan¹, (D) Olcay Evliyaoğlu \\ ${ }^{1}$ Istanbul University Cerrahpasa Faculty of Medicine, Department of Pediatric Endocrinology, Istanbul, Turkey \\ ${ }^{2}$ Ege University Faculty of Medicine, Department of Medical Genetics, Izmir, Turkey
}

\section{What is already known on this topic?}

In childhood, pheochromocytomas (PCC) are mostly due to genetic causes, of which von Hippel-Lindau (VHL) disease is the most frequent disorder. VHL may be the only and/or initial manifestation of the disease, with delayed manifestations of the syndrome in other organs.

\section{What this study adds?}

We report two cases of von Hippel-Linda (VHL) disease who presented with pheochromocytomas (PCC). In the second case, pancreatic neuroendocrine tumor (PNET), a very rare manifestation of VHL disease, developed during follow-up. To the best of our knowledge, this is only the second case in the literature presenting with a combination of PNET and PCC in childhood.

\begin{abstract}
von Hippel-Lindau (VHL) disease is an autosomal dominantly inherited disorder, characterized by hemangioblastomas of the retina and central nervous system (CNS); renal cysts; clear cell carcinoma; pheochromocytoma (PCC); endolymphatic sac tumors; cystadenomas of the epididymis in males; broad ligament of uterus in females; pancreatic cysts; cystadenomas; and neuroendocrine tumors. We report two cases of VHL disease that presented with PCC as the first manifestation. Further clinical developments during follow-up, hemangioblastoma of CNS in one case and a pancreatic neuroendocrine tumor (PNET) in the second case led to the diagnosis of VHL disease. Genetic analyses of the two cases revealed p.Arg161Gln (c.482G > A) and p.Leu129Pro (c.386T > G) heterozygous missense mutations in the VHL gene, respectively. In children, PCC may be the only and/or initial manifestation of VHL with delayed manifestations of the syndrome in other organs. PNET is a very rare manifestation of VHL disease. To the best of our knowledge, this is only the second reported case presenting with a combination of a PNET and bilateral PCC as components of childhood VHL disease. Pediatric patients diagnosed with PCC should be investigated for genetic causes and especially for VHL.
\end{abstract}

Keywords: von Hippel-Lindau syndrome, pheochromocytoma, pancreatic neuroendocrine tumor, hemangioblastoma

\section{Introduction}

von Hippel-Lindau (VHL) disease is an autosomal dominantly inherited disorder caused by a germline mutation in the VHL tumor supressor gene. VHL is characterized by hemangioblastomas of the retina and central nervous system
(CNS); renal cysts; clear cell carcinoma; pheochromocytomas (PCC); endolymphatic sac tumors; cystadenomas of the epididymis in males and broad ligament of uterus in females; pancreatic cysts, cystadenomas and neuroendocrine tumors $(1,2)$. Incidence of VHL disease is estimated at 2-3 cases per 100000 population (3). If a family history of VHL disease is 
present, a diagnosis of VHL disease can be made by finding only a single VHL-associated tumor. On the other hand, approximately $20 \%$ of VHL cases are sporadic and in these cases the presence of two VHL tumors is necessary to diagnose the disease, in the absence of a positive family history (4).

PCCs are uncommon neuroendocrine tumors that arise from chromaffin cells of the adrenal medulla and produce excessive amounts of catecholamines, which are responsible for hypertensive surges, palpitations, headache, and diaphoresis (5). PCCs are rare in childhood but represent a curable cause of hypertension and must be considered in the differential diagnosis of hypertension. Compared with adults, children with PCCs have a higher incidence of bilateral adrenal tumors, extra-adrenal tumors and multiple tumors (6). Although most PCC cases are sporadic, more than $25 \%$ are associated with an inherited mutation and this ratio can be as high as $55 \%$, if diagnosed before 18 years of age (7). In childhood, PCCs are mostly due to genetic causes, in which VHL disease is the most frequent disorder (8). PCCs in VHL disease tend to be seen at younger ages, are often multiple and may be extra-adrenal $(9,10)$.

Here we report two cases of VHL disease, who presented with PCC as the first manifestation. Further clinical developments during follow-up, hemangioblastoma of CNS in the first case and pancreatic neuroendocrine tumor (PNET) in the second case, led to the diagnosis of VHL disease.

\section{Case Reports}

\section{Case 1}

This patient was a twelve year old boy, admitted with complaints of weight loss, hot flushes, palpitation and diaphoresis, for the past one month. He was the first child of nonconsanguineus parents. His birth history was unremarkable. His family history was not significant for tumor occurrence. On physical examination, he weighed $43 \mathrm{~kg}$ [-0,28 standard deviation (SD)]. Height was $150 \mathrm{~cm}$ $(-0,48 \mathrm{SD})$. His blood pressure was 140/100 mmHg (95p $123 / 81 \mathrm{mmHg}$ ), heart rate was 115 beats per minute. General examination was otherwise normal.

Laboratory tests showed an elevated 24 hour (h) urinary vanillylmandelic acid (VMA) concentration of $115 \mathrm{mg} /$ day (normal value $<15 \mathrm{mg} /$ day). An abdominal ultasound revealed solid lesions, $27 \times 35 \mathrm{~mm}$ at the right adrenal gland and $37 \times 75 \mathrm{~mm}$ at the left adrenal gland. Abdominal magnetic resonance imaging (MRI) showed bilateral adrenal masses compatible with PCC. Bilateral subtotal adrenalectomy, including removal of the masses, was performed and the diagnosis of bilateral PCC was confirmed histologically. The patient remained asymptomatic with no laboratory or radiologic abnormalities for five years of follow-up. At the age of 17, he presented complaining of headache. Cranial MRI demonstrated a lesion of one centimetre diameter, located in the left frontal lobe. Positron emission tomography (PET) revealed a lesion of increased 18 fluorodeoxyglucose uptake in the right adrenal gland, compatible with recurrence, and a hypometabolic, hypodense focus in the left frontal lobe (Figure 1). The cranial mass was excised and hemangioblastoma was diagnosed histologically. Adrenalectomy was performed for the lesion in the right adrenal gland and recurrence of PCC was confirmed. Coexistence of PCC and cranial hemangioblastoma suggested the diagnosis of VHL disease. The previously reported heterozygous missense mutation c. 482G > A (p. Arg161Gln) in the VHL gene was detected on genetic analysis.

\section{Case 2}

This 10 year old girl presented with intermittent fever for the past one month. Her birth history was unremarkable. She was the fourth child of nonconsanguineous parents. Her family history was not significant for tumor occurrence. Physical examination revealed a blood pressure level of 160/100 mmHg (95p: 120/79 mmHg) and a heart rate of 110 beats per minute. Laboratory tests showed an elevated $24 \mathrm{~h}$ urinary VMA level of $83 \mathrm{mg} /$ day. Abdominal MRI revealed a 44x33 $\mathrm{mm}$, well circumscribed mass with a necrotic core in the left adrenal gland. Subtotal adrenalectomy was performed and histologic examination showed that the tumor was PCC.

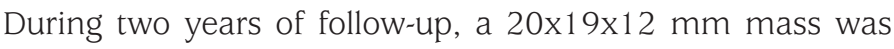
detected in the right adrenal gland on abdominal MRI. PET-

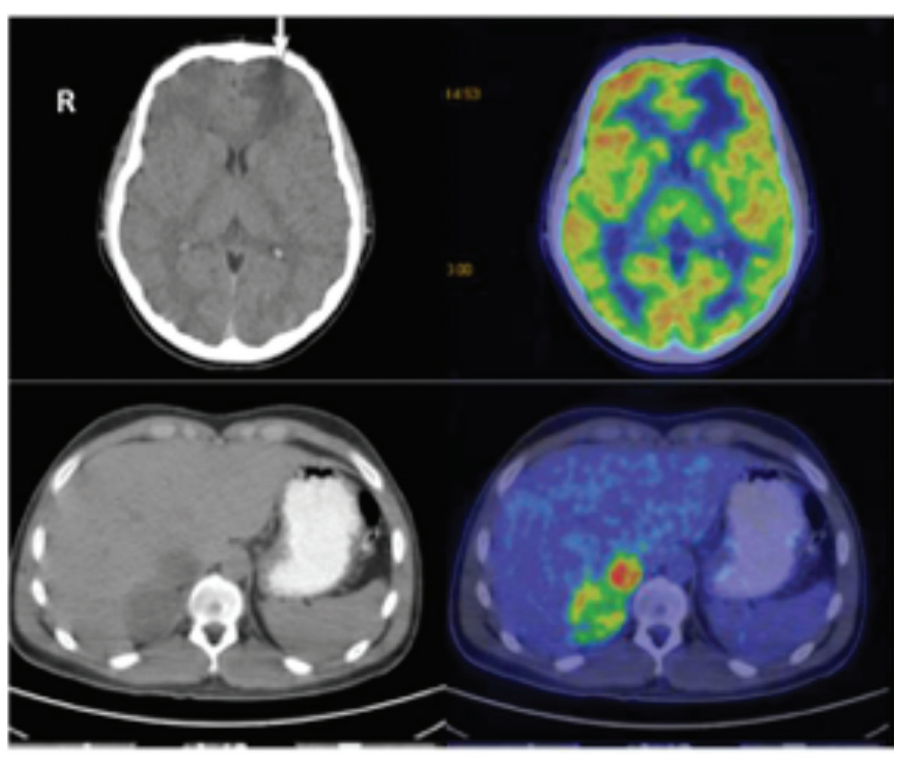

Figure 1. Positron emission tomography imaging showing increased fluorodeoxyglucose uptake in the right adrenal gland, compatible with recurrence, and hypometabolic, hypodense focus in the left frontal lobe 
computed tomography (CT) with ${ }^{68} \mathrm{Ga}-\mathrm{DOTA}-\mathrm{DPh} \mathrm{H}^{1}$, $\mathrm{Tyr}^{3}$ octreotate $\left({ }^{68} \mathrm{Ga}\right.$ - DOTATATE) showed increased uptake in the right adrenal gland and a $11 \times 10 \mathrm{~mm}$ nodular lesion in the corpus of the pancreas (Figure 2). The tumoral masses in the adrenal gland and pancreas were removed. Histologic investigation of adrenal and pancreas specimens confirmed the diagnosis of PCC and PNET (World Health Organisation grade 3) respectively. One year later, an $8 \times 7 \mathrm{~mm}$ lesion in the pancreas, compatible with recurrence, was observed on abdominal MRI and confirmed with 68 Ga-DOTATATE PET-CT. Splenectomy and subtotal pancreatectomy were performed for removal of the lesion. Histologic examination of the pancreatic lesion reported a neuroendocrine tumor. Bilateral PCC with PNET suggested the diagnosis of VHL disease. Molecular genetic analysis of the VHL gene revealed a heterozygous missense mutation c. 386 T > G (p.Leu129Pro) which has been previously described. No additional VHL tumor developed during three years follow up.

Both patients are being followed up according to the recommended pediatric screening protocol for children carrying a VHL mutation (11).

\section{Genetic Analysis}

Molecular DNA was isolated from a $200 \mu \mathrm{L}$ blood sample using the QIAamp DNA Blood Mini QIAcube Kit with a QIAcube instrument (QIAGEN, Hilden, Germany) according to the manufacturer's specifications. The full coding sequences, including the $5^{\prime}$ untranslated region (UTR) and the $3^{\prime}$ UTR of the VHL gene (OMIM*608537), were amplified and sequenced. PCR products were purified using ExoSAPIT (GE Healthcare, Little Chalfont, UK). The PCR fragments were sequenced by using the BigDye terminator V3.1 Cycle Sequencing ready reaction system (Applied Biosystems, Foster City, CA, USA) according to the manufacturer's instructions. Sequence analysis was performed on an ABI Prism 3100-Avant DNA sequencer (Applied Biosystems).

\section{Discussion}

PCC is an exceptionally rare neoplasm in children, accounting for $1 \%$ of pediatric hypertensive patients (12). Of all PCC

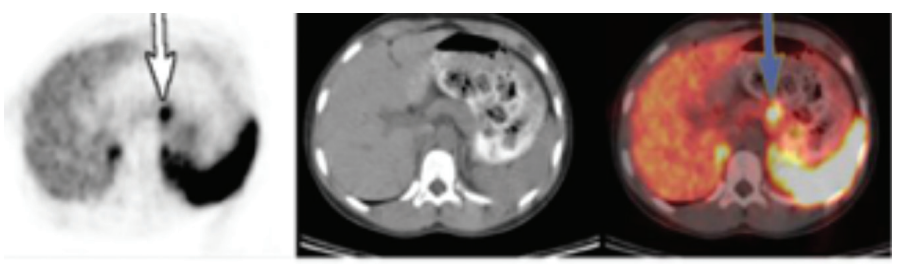

Figure 2. Positron emission tomography - computed tomography imaging showing increased uptake in the right adrenal gland and $11 \times 10 \mathrm{~mm}$ nodular lesion in corpus of the pancreas cases, approximately $10-20 \%$ are reported to occur in the pediatric population (13). Childhood PCC is associated with sustained hypertension, whereas PCC in adults is characterized by hypertensive attacks with the classical triad of palpitation, headache and sweating (14). Episodic tachycardia, sweating and hot flush, the classic symptoms of PCC, accompanied by sustained hypertension, were present in our first patient. However, in the second case, the only symptom was intermittent fever. However, sustained hypertension was detected on physical examination.

PCCs are seen both sporadically and in association with a number of familial cancer syndromes such as VHL disease, multiple endocrine neoplasia type 2, paraganglioma syndromes type 1, 3 and 4, and, rarely, in neurofibromatosis (13). Family history was negative for familial cancer syndromes in both cases. Even in patients with apparently sporadic PCCs, up to $25 \%$ will have unsuspected germline mutations. Younger age and multifocal tumors, as in our patients, are significantly associated with the presence of a mutation. Genetic testing may detect patients at risk for other associated tumors (15). The delayed diagnosis of VHL disease was made after the occurrence of cranial hemangioblastoma in the first case and PNET in the second case.

In childhood and adolescence, PCC may be the only initial manifestation of VHL disease with delayed manifestations of the syndrome in the eye, CNS or other organs (16).

VHL disease is classified into four subtypes. type 1 occurs without PCC while type 2A, 2B and $2 \mathrm{C}$ all carry the risk of development of PCC. Patients with type 2A have a low risk of renal cell carcinoma (RCC) while Type 2B patients have a high risk of RCC. VHL type $2 \mathrm{C}$ confers an increased risk of PCCs without other manifestations of the disease. In type 1 families, deletions in the VHL gene are often detected, whereas in type 2 disease, missense mutations are most often encountered. In our cases, the presence of PCC and the missense mutations in VHL gene suggested VHL type 2. Mutation found in the first patient, c.482G > A (p. Arg161 Gln), is also known to be associated with RCC $(17,18)$. However, to date, our patients have not shown any signs of RCC.

Involvement of the pancreas in VHL disease has been reported in $25 \%$ to $70 \%$ of cases (19). In most of the cases, pancreatic changes are characterized by benign cysts (20). In VHL disease, neuroendocrine tumors of the pancreas and PCCs are observed in $8-17 \%$, and $10-20 \%$ of patients respectively (21). The association of neuroendocrine tumors of the pancreas with PCCs has been reported in $12 \%$ of patients with VHL disease (22). Pancreatic tumors rarely occur during childhood (23). The mean age at presentation for neuroendocrine tumours is 35 years (21). In our second case, PNET as a component of VHL was detected at the age of 
twelve years, two years after diagnosis of PCC. Langrehr et al (24) reported a 12-year-old girl with c.695 G > A mutation in exon 3 of the $V H L$ gene resulting in a neuroendocrine tumor of the pancreas and bilateral adrenal PCC. To the best of our knowledge, our patient is the second youngest reported case in the literature, presenting with a combination of PNET and bilateral PCC as components of childhood VHL disease.

To conclude, we have presented two childhood cases of VHL disease with bilateral PCC and an additional tumor, namely PNET and cranial hemangioblastoma diagnosed after two and five years after the initial diagnosis of PCC, respectively. The combination of PCC and PNET in childhood VHL disease is here reported for only the second time in the literature. Meticulous follow-up and early genetic testing in PCC may facilitate diagnosis and serve to prevent morbidity and mortality, as well as improving long term prognosis in VHL disease.

\section{Ethics}

Informed Consent: The inform consent was taken from the patients' parents for publication.

Peer-review: Externally peer-reviewed.

\section{Authorship Contributions}

Surgical and Medical Practices: Aydilek Dağdevren Çakır, Hande Turan, Ayça Aykut, Asude Durmaz, Oya Ercan, Olcay Evliyaoğlu, Concept: Aydilek Dağdeviren Çakır, Olcay Evliyaoğlu, Oya Ercan, Design: Aydilek Dağdeviren Çakır, Olcay Evliyaoğlu, Oya Ercan, Data Collection or Processing: Aydilek Dağdeviren, Hande Turan, Ayça Aykut, Analysis or Interpretation: Ayça Aykut, Asude Durmaz, Literature Search: Aydilek Dağdeviren Çakır, Hande Turan, Writing: Aydilek Dağdeviren Çakır, Olcay Evliyaoğlu, Oya Ercan.

Financial Disclosure: The study received no financial support.

\section{References}

1. Richard S, Graff J, Lindau J, Resche F. Von Hippel Lindau disease. Lancet 2004;363:1231-1234

2. Shuin T, Yamasaki I, Tamura K, Okuda H, Furihata M, Ashida S. Von HippelLindau disease: molecular pathological basis, clinical criteria, genetic testing, clinical features of tumors and treatment. Jpn J Clin Oncol 2006;36:337-343.

3. Friedrich CA. Von Hippel-Lindau syndrome: a pleomorphic condition. Cancer 1999;86(11 Suppl):2478-2482.

4. Maher ER, Neumann HP, Richard S. Von Hippel-Lindau disease: a clinical and scientific review. Eur J Hum Genet 2011;19:61 7-623. Epub 2011 Mar 9

5. Martucci VL, Pacak K. Pheochromocytoma and paraganglioma: diagnosis, genetics management and treatment. Curr Probl Cancer 2014;38:7-41. Epub 2014 Jan 15

6. Beltsevich DG, Kuznetsov NS, Kazaryan AM, Lysenko MA. Pheochromocytoma surgery: epidemiologic peculiarities in children. World J Surg 2004;28:592596
7. Sbardella E, Cranston T, Isidori A, Shine B, Pal A, Jafar-Mohammad B, Sadler G, Mihai R, Grosmann AB. Routine genetic screening with a multi-gene panel in patients with pheochromocytomas. Endocrine 2018;59:175-182. Epub 2017 May 5

8. Barontini M, Levin G, Sanso G. Characteristics of pheochromocytoma in a 4- to 20-year-old population. Ann N Y Acad Sci 2006;1073:30-37.

9. Walther MM, Reiter R, Keiser HR, Choyke PL, Venzon D, Hurley K, Gnarra JR, Reynolds JC, Glenn GM, Zbar B, Linehan WM. Clinical and genetic characterization of pheochromocytoma in von Hippel- Lindau families: comparison with sporadic pheochromocytoma gives insight into natural history of pheochromocytoma. J Urol 1999;162:659-664.

10. Aufforth RD, Ramakant P, Sadowski SM, Mehta A, Trebska-McGowan K, Nilubol N, Pacak K, Kebebew E. Pheochromocytoma Screening Initiation and Frequency in von Hippel Lindau Syndrome. J Clin Endocrinol Metab 2015;100:4498-4504. Epub 2015 Oct 9

11. Prasad R, Johnston LB, Savage MO, Martin L, Perry LA, Storr HL. Pediatric endocrine screening for von Hippel-Lindau disease: Benefits and the challenge of compliance. J Endocrinol Invest 2011;34:296-299. Epub 2010 Jun 28

12. 12. Armstrong R, Sridhar M, Greenhalgh KL, Howell L, Jones C, Landes C, McPartland JL, Moores C, Losty PD, Didi M. Phaeochromocytoma in children. Arch Dis Child 2008;93:899-904. Epub 2008 May 22

13. Erlic Z, Neumann HP. Familial pheochromocytoma. Hormones (Athens) 2009;8:29-38

14. Bissada NK, Safwat AS, Seyam RM, Al Sobhi S, Hanash KA, Jackson RJ, Sakati N, Bissada MA. Pheochromocytoma in children and adolescents: a clinical spectrum. J Pediatr Surg 2008;43:540-543.

15. Neumann HP, Bausch B, McWhinney SR, Bender BU, Gimm O, Franke G, Schipper J, Klisch J, Altehoefer C, Zerres K, Januszewicz A, Eng C, Smith WM, Munk R, Manz T, Glaesker S, Apel TW, Treier M, Reineke M, Walz MK, Hoang-Vu C, Brauckhoff M, Klein-Franke A, Klose P, Schmidt H, MaierWoelfle M, Peçzkowska M, Szmigielski C, Eng C; Freiburg-Warsaw-Columbus Pheochromocytoma Study Group. Germ-line mutations in nonsyndromic pheochromocytoma. N Engl J Med 2002;346:1459-1466

16. Barontini M, Dahia PL. VHL disease. Best Pract Res Clin Endocrinol Metab 2010;24:401-413

17. Zbar B, Kishida T, Chen F, Schmidt L, Maher ER, Richards FM, Crossey PA, Webster AR, Affara NA, Ferguson-Smith MA, Brauch H, Glavac D, Neumann HP, Tisherman S, Mulvihill JJ, Gross DJ, Shuin T, Whaley J, Seizinger B, Kley $\mathrm{N}$, Olschwang S, Boisson C, Richard S, Lips $\mathrm{CH}$, Lerman M, et al. Germline mutations in the Von Hippel-Lindau disease (VHL) gene in families from North America, Europe, and Japan. Hum Mutat 1996;8:348-357.

18. Glasker S, Bender BU, Apel TW, Natt E, van Velthoven V, Scheremet R, Zentner J, Neumann HP. The impact of molecular genetic analysis of the VHL gene in patients with haemangioblastomas of the central nervous system. J Neurol Neurosurg Psychiatry 1999;67:758-762.

19. Maher ER, Kaelin WG Jr. von Hippel-Lindau disease. Medicine (Baltimore) 1997;76:381-391

20. Neumann HP, Dinkel E, Brambs H, Wimmer B, Friedburg H, Volk B, Sigmund G, Riegler P, Haag K, Schollmeyer P, et al. Pancreatic lesions in the von HippelLindau syndrome. Gastroenterology 1991;101:465-471.

21. Lonser RR, Glenn GM, Walther M, Chew EY, Libutti SK, Linehan WM, Oldfield EH. von Hippel-Lindau disease. Lancet 2003;361:2059-2067.

22. Hammel PR, Vilgrain V, Terris B, Penfornis A, Sauvanet A, Correas JM, Chauveau D, Balian A, Beigelman C, O’Toole D, Bernades P, Ruszniewski P, Richard S. Pancreatic involvement in von Hippel-Lindau disease. The Groupe Francophone d'Etude dela Maladie de von Hippel-Lindau. Gastroenterology 2000;119:1087-1095.

23. Shorter NA, Glick RD, Klimstra DS, Brennan MF, Laquaglia MP. Malignant pancreatic tumors in childhood and adolescence: the Memorial SloanKettering experience, 1967 to present. J Pediatr Surg 2002;37:887-892.

24. Langrehr JM, Bahra M, Kristiansen G, Neumann HP, Neumann LM, Plöckinger U, Lopez-Hänninen E. Neuroendocrine tumor of the pancreas and bilateral adrenal pheochromocytomas. A rare manifestation of von Hippel-Lindau disease in childhood. J Pediatr Surg 2007;42:1291-1294. 